\title{
Translation as Renarration: Critical Analysis of Iran's Cultural and Political News in English Western Media and Press from 2000 to 2012
}

\author{
Aliakbar Pormouzeh \\ MA (Master of Art) in Translation Studies \\ Islamic Azad University Science and Research Branch, East Azerbaijan, Iran \\ a.pormouzeh@yahoo.com
}

\section{Doi:10.5901/mjss.2014.v5n9p608}

\section{Abstract}

This study is an attempt to analyze narrative theory and apply translation assessment model of narrative paradigm on Iran's translation of cultural and political narratives in western media and press from 2000 to 2012. Referring to Baker's statement that narratives or stories constitute reality than merely representing it, the paradigm shift led scientists to develop the principles of narrative theory and narrative paradigm in translation studies. To this end, 15 samples from events of Iran's cultural and political news were selected from western media and news agencies. Four features of narrative theory were applied with respect of equivalence between both Persian and English narratives descriptively, and then assessment model of narrative paradigm was conducted analytically on mere English samples. The results of the study show that four kinds of interfering factors initiated by translators and institutions, namely interference that shapes the text, thematic selection, reframing and selecting translational values as ideological instruments involve in the process of translation in renarrating Iran's cultural and political news in the western media and news agencies. Also, the assumption referring to the statement "narratives are instrument of mind of translators" is rejected. Finally, the narrative paradigm assumption that indicates narratives constitute reality than merely representing them is supported with respect to the renarration of Iran's cultural and political news in the western media and press.

Keywords: narrative theory, narrative paradigm, renarration, construction, representation, reframing, meta-narrative, temporality, relationality, casual emplotment, selective appropriation.

\section{Introduction}

Translation has been defined differently during the time based on necessities and consideration of the time. Baker (2008) stated that 'renarration' is a new metaphor for translation. Because the previous notions of translation such as 'faithfulness' and 'equivalence effect' are linguistically driven and less discourse based, they can not satisfy translation theory; therefore, renarration is another metaphor for translation. Regardless of what is the fact in the world, narratives and renarrations of events are not completely the same in telling details by composition and translation.

It is believed that translators and interpreters' faithfulness to ideology and power relations in the field of translation makes the process of decision making a difficult task. In some situations, especially the situation of conflict -by existing different narrations of the same fact- translators and interpreters are expected to take the neutral position, but practically it is not possible, because they are rented by commissioners and institutions in order to obey the respected values of those organizations. For this reason, translation changes and sometimes deviates from moralities and ethics of translation. In fact, countries are restricted to their beliefs and ideologies, so they never endanger their interests to depict other cultures and ideologies as they are, but shape them through renarration, reframing, and construction in favor of their expedients and policies, not direct and unchanging representation of cultural, social and even political facts.

The problem arises when dominant countries regardless of the facts and their portion in the conflicts reverse the facts differently in translation. Narrative theory defined by Mona Baker (2006) as 'public and personal 'stories' that we subscribe to and that guide our behavior. They are the stories we tell ourselves, not just those we explicitly tell other people, about the world(s) in which we live. The terms 'narrative' and 'story' are interchangeable in this context" (2006, p. 19). From the above definition of the narrative theory the researcher imagines that what has been told or written as composition or translation about Iran might not be the real understanding of cultural and political events of Iran, and they might be stories or narratives in their own.

In this study the researcher has considered renarration and reconstruction of Iranians in translation and interpretation of cultural and political news since 2000 to 2012 to understand the reasons that shape the narrative 
account of Iran's cultural and political identity then applying Walter Fisher's narrative paradigm the researcher assessed narratives to find rationality and reality of narratives.

This study is an attempt to investigate narrative theory and its features to closely examine narrations and renarrations of Iranians' cultural and political news in western media and news websites.

\subsection{Research questions and hypotheses}

1. How do ideological considerations lead to different narratives in translation and interpretation of cultural and political news of Iran in the media and news websites?

2. How does narrative operate as an instrument of mind in the construction of reality?

3. Given that narrative theory constitutes reality than merely representing it, it is questioned whether this idea is supported in the case of Iranian cultural and political news in the western media and news agencies.

\subsection{Research hypothesis}

1. Different narratives of cultural and political news of Iran in English media and news websites are by-product of ideology of patronages.

2. Narratives are translators' specific instruments of mind in the construction of reality.

3. Narrating Iranian cultural and political news in the western media and news agencies is approximately the reconstruction of reality than merely the representation of it.

\section{Literature Review}

The basis of Baker's (2006) work in narrative theory is conflict and power that shapes different narratives of the world. She states that "conflict refers to a situation in which two or more parties seek to undermine each other because they have incompatible goals, competing interests or different values" (Baker 2006, p. 1). She considers conflict in political sense that is hostility between races, religions or nation states. Narrative theory refers to the aspect of social and communicative theory of narativity and to some extent corresponds with Foucault's discourse theory and differs from the term narratology and linguistics, the latter is mostly used in literary texts and the former is based on oral narratives and language production.

Referring to the closest witness of events can represent the real world happenings and translating again and again of a narrative and every retelling of it deviate from the body and soul of reality. In every retelling some merits remain untold and some other details are replaced, also passing from one ideology to another, the fact would be reframed and far from the real reasoning of reality.

Narratives may be looked at from various points of views and perspectives that most of the time is the result of political consideration of narratives. For instance an Act was passed in French government in 2004 about ban of religious symbols for students who attended schools to coordinate different races and religions with the social rules of French society. To this end, they send down some Muslim girls wearing Hijab and also some Jewish students with religious symbols. Therefore, irrespective of considering the right of citizenship in the French and obeying the social rules, different narrations of this act established and evoked the sentiments of thousands of Muslims and they condemned the French government as racist and anti- freedom government (Example quoted from Baker 2006, p. 22). Therefore, these are narratives that shape the world not direct representation of the world. Baker (2006) discusses four types of narrative that are ontological narratives, public narratives, conceptual narratives and meta-narratives.

\subsection{Typology of Narrative}

Narrative theory is a social theory and was not related to the translation until elaboration of it by Mona Baker in "Translation and Conflict: A Narrative Account". In this book, she extensively discusses the issue and relates it to translation studies and also verifies each case study with examples pertinent to the theories.

Ontological or personal narratives are discussed in social studies as "personal stories that we tell ourselves about our place in the world and our own personal history"( Baker, 2006, p. ). These stories are interpersonal and social in nature, because "[t]he person has to exist, to tell their story, in a social world - they are a situated, located self." (Whitebrook 2001, p. 24 cited in Baker 2006, p. 28)

Translating and interpreting ontological narratives is often extremely challenging (Baker 2006, p. 32), Baker 
describes a case study at the University of Durham, UK, described the impact of a child abuse and the translation of the feelings involved in this case. Translation and interpreting are retelling of personal expressions and feelings and interpreter is said to play the role of the person she/he interpret or translate. There are other types of narration that go beyond self and are more public, shared and social.

Public narratives are the stories that construct the world in society and we agreed on them to distinguish the public narratives from the other narratives and similar terms. Baker (2006) states that "public narratives are very similar to but not quite the same as what was referred as shared or collective narratives. 'Shared' or 'collective' narratives are loose terms that tend to be used outside any specific model. They refer vaguely to any type of narrative that has currency in a given community (Baker, 2006, p. 33).

Somers and Gibson (1994) state that public narratives are defined as stories elaborated by and circulating among social and institutional formations larger than the individual, such as the family, religious or educational institution, the media, and the nation. To understand public narrative Baker (2006) presents a more recent example that is the numerous and competing public narratives of 11 September 2001 or the war on Iraq launched by the USA-led 'Coalition' in 2003: Who is responsible? Why did it happen? Could it have been avoided? How many died? (ibid).

Conceptual (disciplinary) narratives are defined by Somers and Gibson (1994, p. 62) as "concepts and explanations that we construct as social researchers". Conceptual narratives may be more broadly defined for our current purposes as the stories and explanations that scholars in any field elaborate for themselves and others about their object of inquiry (Cited in Baker 2006, p. 39).

Conceptual narratives are not concrete and unquestionable, but they are open to contest and development. Theories in which we construct about the world are in the state of change over time. Psychologists are familiar to every one that they tend to classify personalities and so on, but their theories are to better understand the people with different characteristics. Translators and interpreters translate narratives that construct the world and to accommodate these narratives they tend to match these narrations to the interests of society and these translations are more or less renarration.

Meta- narratives or master narratives defined by Somers and Gibson (1994, p. 61) as "narratives in which we are embedded as contemporary actors in history." Also Somers (1992 p. 605) explains that meta-narratives can also be "the epic dramas of our time: Capitalism vs. Communism, the Individual vs. Society, Barbarism/Nature vs. Civility'.

As it is understood meta- narrative is the state in which we role play in, and is politically bounded because it is the result of power that a public narrative becomes meta- narrative. Political powers today deploy to obtain their interests softly. Meta-narrative is different from master plots that are the theme of narratives in literature and is the result of repetition of theme. Meta-narrative is the consequent of enlargement of ideology and culture to invade other beliefs.

The meta-narrative of the Cold War, for example, like the meta-narrative of the War on Terror, was essentially an invention of the American political elite, soon to be followed by other political elites across the globe (ibid). Today, at least, Muslim countries have little or no political power, and yet the meta-narrative of Islam probably has wider currency than any other religious narrative, with hundreds of millions of followers worldwide (ibid).

Finally, it goes without saying that narratives do not travel across linguistic and cultural boundaries, and certainly do not develop into global meta-narratives, without the direct involvement of translators and interpreters (ibid, 48).

Feathers of Narrative Theory

The term temporality calls upon setting a narrative in time sequence, but Baker (2006 p. 50-51) states that "elements of narrative are always placed in some sequence and the order in which they are placed carries meaning." To better understanding of temporality Baker (2006) defines it and explains temporality means that sequence is an organizing principle in interpreting experience. The set of events relationships and protagonists that constitute any narrative has to be embedded in a sequential context and in a specific temporal and spatial configuration that renders them intelligible (2006, p. 51).

The history in considering temporality feature is of prime importance, because events take place in time and place. Narrating chronologically events in history creates some meanings. Also, breaking the chain of events in narrating the history create ambiguity. It is believed that dominant superpowers or empires have written the history- open to challenge in epistemological view.

Events are related to each other and one can not analyze an event in isolation. It seems that an action is the consequence of some other related actions; therefore, without considering the process of related items dealing with an event or narrative of an event, close understanding of reasons is impossible.

The relationality of narratives directly affects translation and in this sense translation could be considered as renarration. Regarding the related discussion Baker (2006, p. 62) concludes that "in the process of importing elements from another narrative both the original narrative and our own narrative are inevitably reconstituted." Therefore, better 
touching upon reality and facts in narratives, events should be discussed related to the time and place of the event and also the context and discourse of that time. This shows that temporality and relationality are inevitable features of narrativity and translation.

Kuhn (1999) considers inability of language in dealing with nature. Because different language terminologies in discussing the nature of narratives are different, therefore the result could be different. Bruner (1991, p. 8) states that "a narrative consists of different parts that make up a whole, but the viability and coherence of that whole depends on how the parts 'mesh together' how they are 'made to live together'(cited in Baker p. 62)". In this regard Baker (idid) defends Bruner's statement and emphasizes that narratives without social and cultural settings are meaningless and if the segregation of narratives from social and cultural setting was possible the translation of narrative could not face any difficulty. She used the term 'contamination' to states that in retelling of narratives in other cultures the new narrative or translation is contaminated with new ideology and situation and also it is in spite of the fact that the original narrative maybe threatened with dilution or change.

One strategy that has been used in translation to touch upon the relationality of the original was using culturally bounded key terms. To give an example related to the Muslim culture is using words like Jihad, Hijab, and Imam. Each word carries a long history with itself to the other culture and by the way translation could be close to the original narrative. But there are other reasons behind this strategy that colonization and other fields of translation such as polysystem theory can explain the issue better.

Somers (1997, p. 82) explains that "causal emplotment gives significance to independent instances and overrides their chronological or categorical order" (cited in Baker, p. 67). Casual emplotment is consideration of events alone without involvement of other occasions related to the event. One can understand an event as it is, but causes and effects of the event could not be discussed without setting the event in the context of the event. In this regard Baker (2006) elaborates the case and represents the example of Israel-Palestine conflict and discusses that there is no discussion over what happened and details, but there is discussion over the hidden forces behind the event. Some narrations consider the Israel attacks on Palestine as a result of Palestinian suicide bombing and other narrative explain the event as a result of Israel attack on philistine. In fact they disagree on the relationship of events and intentions in each set of the events. She also states that "emplotment allows us to weight and explain events rather than simply list them to turn a set of propositions into an intelligible sequence about which we can form an opinion" (p. 67).

Words have connotations and denotations. Just considering the word Jihad in Iranian context one can say that always it doesn't mean holy war. If one considers the independent meaning of this word can say striving for the utmost for in the Iranian culture and context in war time Jihad means only holy fighting against enemies and in peace time using this word means construction of the country by getting together to build it as soon as possible. Selection of words in crosscultural communication that is related to our discussion is of a great importance.

Somers and Gibson (1999) and Baker (2006) argue that narratives are constructed based on evaluative criteria that enable selective appropriation of a set of events. They also state that in a narrative many details remain untold that may be important. In fact narratives are thematically driven, in other words they are selected based on social themes in the society as some elements in the society have a prime importance. Also Polkinghorne (1995) believes that the selection of a narrative is according to the consideration of plot.

It seems that different scholars agree in a narrative theme and plot of other events decide which element should be selected or highlighted. Therefore in selecting events those elements are told that could motivate our behavior, not every worthless detail. Although it doesn't mean that other details are not important. It might reveal that other details are untold for the sake of ideological considerations.

In narrative as a result of selective appropriation some times omission occurs and other elements will be highlighted. Foregrounding is another factor that is used in narrativity.

It seems that narrations are selected based on individual and institutional values. Therefore determination of narratives that are free from prejudice is difficult. To this end Walter Fisher (1997) suggest a narrative Paradigm in witch considers some elements for the assessment of narratives to reveal the reality and facts behind narration and renarration.

\subsection{Walter Fisher's Narrative Paradigm}

How can evaluate narratives? Is it possible to evaluate them? To do so, Fisher suggested a model of narrative assessment. It is believed that no one can measure narratives objectively; the question is that whether we accept a narrative or challenge it?

Narrative paradigm consists of two principles in which define the narrative rationality and the concept of good reason that are coherence and fidelity. 


\subsubsection{Coherence}

Fisher's principle of narrative coherence concerns the internal consistency and integrity of a narrative - how well it hangs together as a story. This involves assessing a narrative with reference to (a) its structural make-up, the way it is organized internally (structural or argumentative coherence); (b) its external consistency and completeness in terms of how it differs from or tallies with other stories on the same issue (material coherence); and (c) 'how it is told' - its believability in terms of the consistency and reliability of the characters involved (characterological coherence). (Baker, 2006, p. 143).

\subsubsection{Fidelity}

Fisher (1987) states that coherence refers to consistency and integrity of the narrative, but fidelity looks like applying the good reason logic and require a narrative examining with value of values. Fidelity consists of reasons and values.

Fisher (1987) states that it is a narrative in terms of the soundness of its reasoning, representation of facts through logic and inference and implicature and contains five components:

- Are the statements indeed fact or are they supported by reliable witnesses

- Is something omitted or distorted or presented out of context

- By standards of informal logic these may relate to the patterns of inference and implicature

- Assessing arguments rather than facts to see the relevance of decision making

- Based on the above we assess the relevance of context and decision.

Fisher (1987) states that values have five components,

- Fact. What implicit and explicit values are embedded in a narrative and we identify them in the narrative

- Relevance. It concerns the relevance of what is presented in the narrative; but the focus here is on values rather than arguments and facts, also concerns omitted, distorted, and misrepresented values.

- Consequence. This criterion focuses on the real world consequences of accepting the values elaborated in the narrative.

- Consistency. Are narratives consistent with one's own experience of the world?

- Transcendent issue or values. Whether the values the message offers... constitute the ideal basis for human conduct, irrespective of the facts and even if a prima-facie case exists or a burden of proof has been established' in relation to a specific narrative. (ibid)

Baker (2006) elaborates the principles of narrative paradigm and states that most of these principles are subjective. It is correct that objective reasoning are the concern of science and science in time is acceptable, but what seems to be logical and approved by virtue of science itself is that science is in the state of change and development during the time, therefore what is in the state of motion is not reliable and applicable all the time. However it necessitates a great courage to state that science is not reliable.

\section{Methodology}

This study investigates narrative theory in translation of Iran's cultural and political news in the western media and news websites. To do so, the researcher has considered15 case studies from media, news websites in English speaking countries along with their correspondent translation during 2000 to 2012 in order to examine the role of ideology in the reconstruction of narrations and finally to assess them according to Fisher's(1984, 1985, 1987, 1997) narrative paradigm.

The model that is applied in this study is Somers and Gibson's (1994) and Baker's (2006) narrative theory and narrative paradigm. They suggested four types of narrative namely, ontological, public, conceptual and meta-narrative. Also, four feathers of narrative theoryare applied in this study that consists of temporality, relationality, casual emplotment and selective appropriation.

This work is not linguistic based or literary oriented design, but it is cross-culturally and cross-border description of cause and effect of the policies behind these narrations. Samples that support our purpose are chosen from BBC News, CNN, and news agencies MEMRI, NYT, and Washington post. These news agencies broadcast the news of landmark events of the world and Iran that is broadcasted in the domestic media and press.

Data analysis, the sequence of analysis is as follow:

1. Selecting the Farsi news and documenting it at the beginning.

2. Selecting the English news (translation) and documenting it after the Farsi news. 
3. Selection criteria (the reason behind selecting narrative will be discussed. News that is considered asmetanarrative is selected).

4. Four features of narrative theory are to be discussed in this part in order to see whether features of narrative in Farsi and English translation are equivalent or not.

5. Assessment (based on Fisher's narrative paradigm)

In this section, coherence and fidelity of narratives are discussed based on the logic of 'good reason' that is a descriptive and qualitative assessment principle. Every statistical data in this part is descriptive and based on 'reason' and 'values' that are indicated in the model and might not be logical to be used for statistical analysis.

\section{Result and Discussion}

It is believed that translation doesn't represent the entire merits of the original text and in this respect Baker (2006) indicates that translation is the reconstruction of the original text than the representation of it. She supports her method by different examples referring to the cases in subtitling and interpreting. The same approach with Baker's analysis of case studies is used in this chapter that was discussed in methodology. Fifteen samples in this study are selected with respect to meta-narrative account in the cultural and political discourse of Iran. English news are selected from media and news websites namely, CNN TV, UC TV, BBC TV, Persian Hub, MEMRI news agency, The New York Times, and Washington Post. The endnote of news referred to the sites or original TV in which the news have been taken from. The English news in some cases is based on different Farsi narrative. The titles of samples are represented below and samples can be accessed on line referring to the archives.

Sample 1. Iran's election documentary, women voting (Persian Hub TV, 2001)

Sample 2. Interview with Iran's President Mohammad Khatami (CNN TV, 2002)

Sample 3. Interview with Shirin Ebadi, Noble Peace Prize Winner in 2003 (UC TV, 2003)

Sample 4. Struggle on Holocaust (MEMRI 2004)

Sample 5. Iran's presidential election 2005, (Los Angeles Times, 2005)

Sample 6. Peaceful Nuclear Energy (MEMRI, 2006)

Sample 7. Capturing British sailors in Iran Waters (Washington Post, 2007)

Sample 8. Friday sermon delivered by Ayatollah Ahmad Khatami (MEMRI TV, 2008)

Sample 9. Rafsanjani in Iran Friday Sermon (MEMRI 2009)

Sample 10. An Open Letter to Hidden Imam, Complaining about Presidential Election of 2009 (MEMERI, 2009)

Sample 11. Ahmadinejad Speeches on Jewish (MEMRI, 2010)

Sample 12. British Embassy Attack (New York Times, 2011)

Sample 13. Drone Crash in Iran (New York Times, 2011)

Sample 14. NAM Conference and Media Censorship (MEMRI, 2012)

Sample 15. Iran Nuclear Death (BBC world news, 2012)

Table 1: shows matching and mismatching of Farsi and English features of narrative namely temporality, relationality, causal emplotment, and selective appropriation.

\begin{tabular}{|c|c|c|c|c|}
\hline samples & Temporality & Relationality & Casual Emplotment & Selective Appropriation \\
\hline Sample1 & $x$ & $x$ & $\checkmark$ & $\checkmark$ \\
\hline Sample2 & $\checkmark$ & $\checkmark$ & $\checkmark$ & $\checkmark$ \\
\hline Sample3 & $\checkmark$ & $\sqrt{ }$ & $\checkmark$ & $\checkmark$ \\
\hline Sample4 & $\checkmark$ & $\checkmark$ & $\checkmark$ & $x$ \\
\hline Sample5 & $\checkmark$ & $\checkmark$ & $x$ & $x$ \\
\hline Sample6 & $x$ & $\checkmark$ & $\checkmark$ & $x$ \\
\hline Sample7 & $x$ & $x$ & $x$ & $x$ \\
\hline Sample8 & $\checkmark$ & $\checkmark$ & $\checkmark$ & $x$ \\
\hline Sample9 & $\checkmark$ & $\checkmark$ & $\checkmark$ & $x$ \\
\hline Sample10 & $\checkmark$ & $\checkmark$ & $x$ & $x$ \\
\hline Sample11 & $x$ & $\checkmark$ & $\checkmark$ & $\checkmark$ \\
\hline Sample12 & $\checkmark$ & $x$ & $x$ & $x$ \\
\hline Sample13 & $\checkmark$ & $\checkmark$ & $x$ & $\checkmark$ \\
\hline Sample14 & $\checkmark$ & $\checkmark$ & $\checkmark$ & $\checkmark$ \\
\hline Sample15 & $\checkmark$ & $x$ & $x$ & $x$ \\
\hline
\end{tabular}


Table 2: assessing samples based of different features of narrative paradigm

\begin{tabular}{|c|c|c|c|c|c|}
\hline Narrative paradigm & \multicolumn{3}{|c|}{ Coherence } & \multicolumn{2}{|c|}{ Fidelity } \\
\hline Features & Structural & Material & Characrological & Reason & Value \\
\hline Sample1 & $\checkmark$ & $\sqrt{ }$ & $\checkmark$ & $\checkmark$ & $\sqrt{ }$ \\
\hline Sample2 & $\checkmark$ & $\sqrt{ }$ & $\checkmark$ & $\checkmark$ & $\sqrt{ }$ \\
\hline Sample3 & $\checkmark$ & $x$ & $x$ & $\checkmark$ & $x$ \\
\hline Sample4 & $\checkmark$ & $x$ & $x$ & $x$ & $x$ \\
\hline Sample5 & $\checkmark$ & $x$ & $x$ & $x$ & $x$ \\
\hline Sample6 & $\checkmark$ & $\sqrt{ }$ & $\checkmark$ & $\checkmark$ & $\checkmark$ \\
\hline Sample7 & $x$ & $x$ & $x$ & $x$ & $x$ \\
\hline Sample8 & $\checkmark$ & $\checkmark$ & $\checkmark$ & $\checkmark$ & $\sqrt{ }$ \\
\hline Sample9 & $\checkmark$ & $\checkmark$ & $\checkmark$ & $\checkmark$ & $\checkmark$ \\
\hline Sample10 & $\checkmark$ & $\checkmark$ & $\checkmark$ & $\checkmark$ & $\sqrt{ }$ \\
\hline Sample11 & $\checkmark$ & $\checkmark$ & $\checkmark$ & $\checkmark$ & $\sqrt{ }$ \\
\hline Sample12 & $\checkmark$ & $\sqrt{ }$ & $\checkmark$ & $\checkmark$ & $\sqrt{ }$ \\
\hline Sample13 & $\checkmark$ & $\checkmark$ & $x$ & $\checkmark$ & $x$ \\
\hline Sample14 & $\checkmark$ & $\checkmark$ & $\checkmark$ & $\checkmark$ & $\sqrt{ }$ \\
\hline Sample15 & $\checkmark$ & $x$ & $x$ & $\checkmark$ & $x$ \\
\hline
\end{tabular}

$\checkmark \quad$ This checkmark shows that English narrative in a specific sample is valid in coherent and fidelity

$\mathbf{x} \quad$ This mark shows that English narratives in a specific sample is invalid in coherent and fidelity

The researcher intended to answer the very beginning questions aroused in this study. To do so, based on analytical discussion and assessments the researcher referring to tables and data inferred from samples answers the research questions.

4.1 Q1. How do ideological considerations lead to different narratives in translation and interpretation of cultural and political news of Iran in the western media and news websites?

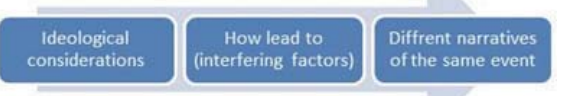

Figure 1: Realization of the research question

The research question itself consists of some questions. One might wonder whether there is fact or unique reality understandable, imaginable and believable for entire human being and how it can be achieved.

Referring back to Baker's (2006) statements about narrative account that every narrative is the reconstruction than the representation events; therefore, there might be no reality or fact behind narratives or if there is any, it is not complete manifestation of the event depicted in the original narrative of the event witnessed by reliable characters. What are the possible influential factors in this process of mismatching narratives?

Based on the results of this study, two factors are involved in the process of mismatching between narratives and facts or reality of the events that are "translator's interference" and "institutions' interference".

\subsection{Translators' interference}

Translators are individuals having complete competence of two or more languages, when we refer to them it means that we believe they are sincere and knowledgeable and also we expected them to do the best possible work. If translator is not able to deal with his/her job, then there would be interference in the text. There are two kinds of translators' interference in the text:

a. Interference or mistranslation that changes the meaning of whole text and questions the consistency of the text.

In fact this kind of mistranslation changes the meaning of the original text in TL. For instance the translation of the following Farsi sentence, 


$$
\begin{aligned}
& \text { يهوديان در جند دهه اخير با نفوذ كسترده خود در مر اكز قدرت بويزه در ارويا و با سوء استفاده از يك دروغ بزرى } \\
& \text { تاريخى موسوم بـه "هولوكاست "معتقدند كهـ ... }
\end{aligned}
$$

as "In recent centuries, the Jews have expanded their influence in the centers of power, particularly in Europe, through the exploitation of a great historic lie called 'the Holocaust" clearly shows that the English translation is mistranslation, because it changes the meaning of the original sentence and make it unbelievable and inconsistent in itself. Also, setting translational view aside, the English statement is not acceptable for Holocaust happened several decades ago, not in recent centuries (pay attention to plural's' in centuries). This is translator's mistake and insufficiency in translational action that makes the narrative unbelievable and contradictory in it. Samples 1,2, and 3 support this idea as there are some cases of mistranslation by translators.

b. Interference that shapes the text.

This kind of interference is not intentional and even is not considered as mistranslation, but influences the translated text and shapes the text in another way. This type of interference is the result of different factors such as surface structure of languages, cultural differences, and figures of speech. Translating a metaphor or symbol literally is unintentional, but in translation it losses the merits of the original figures of speech, these are not mistranslation- in fact the result of translator's bilingual inability. This type of interference in translation is "من در يك خانو اده " renarrating the translation unintentionally. For example in translation of Farsi sentence as "I was born to parents who come from educational backgrounds..." doesn't change the meaning of the text and it is acceptable, consistent and relevance, but may not transfer the merits and perfect meaning of the original concept (translator inability in finding equivalent cultural terms). Sample 1,2,3,4, and 10 support this idea referring to the unintentional translation mistakes that don't change the meaning in translation.

\subsection{Institutional interference}

The term 'institution' is selected for social organizations, news agencies supported by specific parties, religious sects, and political parties. These institutions interfere in the original text and narratives of events. The results of this study (represented in case studies) shows that institutions interfere in the narratives in different ways.

First, they select the cases intentionally and thematically in translation in order to criticize the original narrative argumentations; therefore, they foreground, highlight and select parts of the news that verify their institutional legitimacy regarding misdeeds and contradictory arguments of the original news or text. For instance in the case of NAM conference (2012), it was approved that censorship in the translation of speeches in the media occurred, because government ordered translators to do so. It specifies that the action of translators depended on the guidelines issued to them by the relevant institution to develop or to maintain its ideology. As this censorship strategy revealed out, soon it becomes the headline of English news. Therefore, in this case and similar cases in chapter four the original text is narrated purposefully and intentionally. Sample 4, 5, 8, 10, 11, 14, and 15 support this idea.

Second, institutions reframe the original narrative so that they select some extracts for translation and discuss the issue referring to different narratives. They write introduction to the news, select their favorable headlines, and compare the reason and effect of in the news as narratives. In fact, they reframe the original text as Baker (2006) discusses it as a narrating strategy. In the process of reframing, narrator shapes the readers viewpoint before reading the text. This is considered as injecting institutional ideology to the reader's mind. For example, in sample 11 the English narrative starts with the following editorial sentence,

in a June 16, 2010 speech in the city of Shahre-Kord, in central Iran near Isfahan, Iranian President Mahmoud Ahmadinejad reiterated his anti-Semitic world view, calling the Jews the worst of criminals and claiming that they only appear to be human.

In this example, before reading the translation, editorial sentence prepare and direct the reader based on narrator's ideology toward the text. Therefore, the construction of news and narratives by editorials and discussion in the text intentionally occur to prioritize the institutional ideologies. Sample 4, 5, 6, 9, 10, 11, and 14 support this idea.

Third, institutions define translational values themselves. They disregard faithfulness to the original text, but they evaluate the contextual environment of the event, and use key terms that serve their purposes. This is due to different values and interests of organizations. Also, this is based on changing of narrative over the time. For example, in the sample 10using 'velvet revolution' for 'فتناي با ظاهري مخملي' it is clear that intrigue(فنته) doesn't mean revolution and the translation strategy involved to distinguish between two parties in the Iran and legitimize one to the other. In fact, this 
shows that it is neither mistranslation nor cultural deviation, but tries to restore the common concepts used for such activities. Of course, this is intentional and ideological consideration in the translational action. Sample 1, 2, 7, 10, 13, 14, and 15 support this idea.

Therefore, results supported by discussion on samples show that Iranian's narration of cultural and political news in the western media and websites is byproduct of interfering factors in the process of translation. These factors are translators and institutions; former interference in translation is unintentional by mistranslation and interference in the translation that reshapes the translated text. Latter interfere in the translation intentionally and purposefully by strategies of thematic selection, reframing and selecting translational values for the text. Figure 4.2 shows interfering factors in the translation. Except 'interference as mistranslation' all other interfering factors influence on Iranian cultural and political narration during 2000 to 1012.

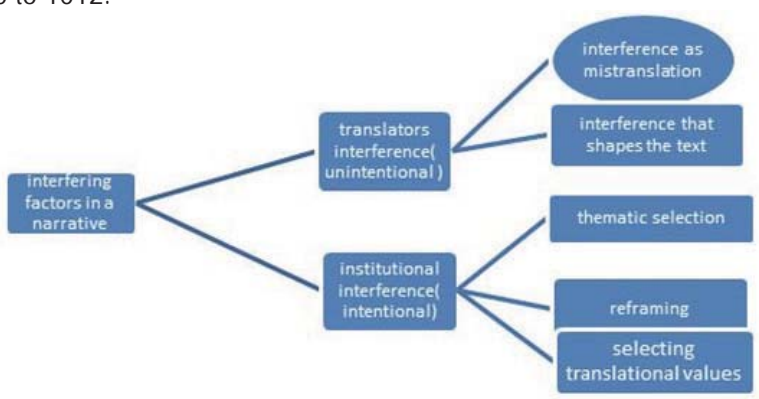

Figure 2: Influncial factors that interfer in the translation intentioally and unintentionally.

As translators are directly involved in the process of translation and they decide based on guidelines and organizational charts (issued by institutions), based on figure 4.2 refering to translators unintencional interference that shapes and reshapes the translated text (i.e. individual diffrences, structure of languages and so on) we conclude that translators are forced to act based on institutions' will. The ideology of actors (institusions) behind translation indirectly determines what translation or narrative needs to be. Figure 4.3 exactly depicts the situation of translateors in the process of translation and narration, it shows that they inevaitably mediate in the process of translation without any authority to change or manipulate the text individualy.

Finally, based on the results of this study the hypothesis reading as "Different narratives of Iran's cultural and political news in English media and news websites are by-product of ideology of patronages" is valid.

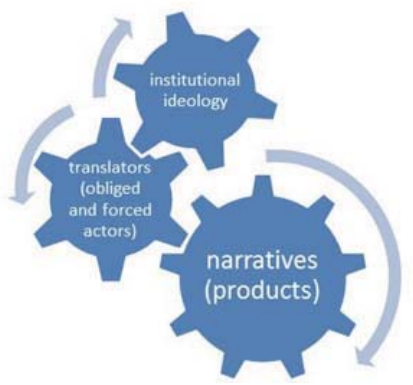

Figure 3: Translators are unintentionally involved in the act of translation and renarration.

\subsection{Q2. How narrative operates as an instrument of mind in the construction of reality?}

Answering this question, one needs to be familiar with the concept of 'instruments of mind'. Mind is the most important instrument of translator and interpreter. It is imagined that translators and interpreters have translation competence when they are employed by legal agencies to do translation. Mind is able to control physical and mental activities; therefore, language skills are instrument of mind. Narratives (composition and translation) are instrument of mind and translator is able to control them in any way he/her wishes. Also, mind acts in its relations with the world. This question draws upon 
psychological factors involved in the act of translation. Is man a reliable teller or narrator? The logical sequence of a narrative is represented in Baker's (2006) features of narrativity. In Baker's opinion narrative as a product determines the translators and narrators legitimacy. Contradictory argumentations and illogical sequence or order of narrating an event are considered as the top factors that represent the translator's illegitimacy. Manner of handling a narrative is meaningful in the original language, changing the order or arguments of a narrative ( by transformation of features of a narrative) changes the theme as it is obvious in most of the samples and there is no one to one consideration of narrative features. For example in the case of Farsi sentence "من ميحم مقنع يعنى اينكة راحته" translated as "And cover your heads with Hijab" interpreter changed the argument and mental consideration of the original narrative and violated temporality and relationality feature of narrative in translation.

In fact, translators by changing the features of narrative from the original text to translation text interfere in the text and construct the reality rather than the representation of it( consideration of narrative features in English narratives are based on reality and fact arguments derived from the Farsi narratives). Based on the finding of this study that is summarized in table 4.16 we conclude that:

With respect to the temporality feature of narrative theory there is no equivalence between Farsi and English news in sample 1, 6, 7, and 11 .

With respect to the relationality feature of narrative theory there is no equivalence between Farsi and English news in sample 1, 7,12, and 15 .

With respect to the casual emplotment feature of narrative theory there is no equivalence between Farsi and English news in sample5, 7,10,12,13, and 15.

With respect tothe selective appropriation feature of narrative theory there is no equivalence between Farsi and English news in sample 4, 5,6,7,8,9,10,12, and 15 .

Also sample 2, 3, and 14indicate that there is complete equivalence with respect to all four features of narrative theory.

Finally, we conclude that 12 samples out of 15 do not match at least in one feature of narrative theory. The result of features of narrative theory in translated text indicates that translators and interpreters interfere in the translation and change the features of original narratives. As the result of this study reveal, and also discussed in detail in the answer of the first question translators change the narratives unintentionally under obligation of institutions and commissioners (figure 4.3). So, we can infer that the construction of reality and facts happens by changing the features of narratives as instruments of mind of translators (unintentionally) directed by institutions (intentionally). Therefore, research hypothesis reading as "Narratives are individual (translators) specific instruments of mind in the construction of reality" is invalid.

\subsection{Q3. Given that narrative theory constitutes reality than merely representing it, it is questioned whether this idea is} supported in the case of Iranian cultural and political news in the western media and news agencies?

Landau (1997) and Baker (2006) assumed that narratives constitute reality rather than merely representing it. They indicated that as it is improbable to access a fact objectively, they said whether it is possible to evaluate a narrative in order to subscribe to or challenge it. Walter Fisher's influential narrative paradigm $(1984,1985,1987,1997)$, provides a method of analyzing the effectiveness of individual narratives. In this study, we evaluated the samples based on narrative paradigm that consists of two basic tenets namely 'coherence' and 'fidelity'. Coherence itself consists of structural, material, and charactrological coherence and fidelity consists of reason and value. Descriptive and qualitative analysis of samples reached us at some results that are documented in data analysis and assessment of samples (tables 4.1 to 4.15). Based on data analysis we obtained the following conclusions:

There is no structural coherence in sample 7.

There is no material coherence in samples $3,4,5,7$, and 15.

There is no character logical coherence in samples 3,4, 5, 7,11,13, and 15.

There is no reasonable fidelity in samples $4,5,7$, and 11 .

There is no valuable fidelity in samples $3,4,5,7,11,13$, and 15 .

Also based on these results we can infer that:

7 out of 15 samples are the reconstruction of realty at least in one assessment criterion.

8 out of 15 samples are the representation of reality and fact of original narrative and event.

There is a significant relationship between character logical coherence and valuable fidelity.

Therefore we conclude that when there is no charactrological coherence (translator) in a narrative, then there would not be fidelity with respect to values. Also, Iranian cultural and political news in the western media and news agencies are relatively constitution of reality than the representation of them and research hypothesis reading as 
"narrating Iranian cultural and political news in the western media and news agencies is approximately the reconstruction of reality and fact than merely the representation of it" is supported.

\section{Conclusion}

This research used narrative theory and narrative paradigm to discuss and assess Iran's translation of cultural and political narratives in western media and news websites from 2000 to 2012. For this reason 15 samples from events of Iran's cultural and political news were selected from western media and news agencies. The researcher intended to analyze the image of Iran in the media and press during the period of 12 years. The samples were selected randomly from the most controversial media and press that is written based on the western ideology. . Narrative theory consists of four types of ontological, public, conceptual, and meta-narrative, also it contains four main features of temporality, relationality, causal emplotment, and selective appropriation. Narrative paradigm that is a model of assessing narratives involves two basic tenets of coherence and fidelity. In the context of Iran's translation of cultural and political narratives it is questioned how do ideological considerations lead to current renarration of Iran's events in the western media and news websites? Having considered the role of translators in this process of translation it is asked how narratives operate as instrument of mind in constructing reality. Also, it is questioned whether narrative paradigm's basic claims referring to constituting reality are supported by results of this study.

The results of the study show that four kinds of interfering factors initiated by translators and institutions, namely interference that shapes the text, thematic selection, reframing and selecting translational values as ideological instruments involve in the process of translation in renarrating Iran's cultural and political news in the western media and news agencies. Also, the assumption referring to the statement "narratives are instrument of mind of translators" is rejected. Finally, the narrative paradigm assumption that indicates narratives constitute reality than merely representing them is supported with respect to the renarration of Iran in the western media and news agencies.

This analysis is inevitably conducted from the researcher's narrative location, it means that others applying the same system may come up with different results of the same narrative; while I challenge a specific narrative others subscribe to and support it. Fisher's narrative paradigm enables us to articulate our reasons to support or to oppose any given narrative.

This study is not without any weakness, nor does it claim. Also, criteria for evaluating any genre of narrative may differ that in turn it represents the nature of assessment principles. Finally, of the privileges of narrative theory might be the importance it gives to values than the traditional logic toward making decisions about narratives and stories.

\section{References}

Associated Press, November 29, 2011

Baker, M. (2006). Translation and conflict: A narrative account. London and New York: Routledge.

Baker, M. (2008). Ethics of renarration: Baker is interviewed by Andrew Chesterman. Cultus1(1): 10-33

BBC world news .5/15/2012, 08:05)

Bruner, Jerome (1991) 'The Narrative Construction of Reality', Critical Inquiry 18(1): 1-21.Even-Zohar, 1990

Channel 1 (Iran) translated by MEMRI TV - August 15, 2008)

Channel 1 TV, Iran (2008) translated by MEMRI TV - August 15, 2008

CNN TV (2002) Interview with Iran's President Mohammad Khatami, Feb 1, 2002.

Ebadi, Sh. (2006). Interviewed by California University, audio.http://www.uctv.tv/cwh/

Farsnews (2006) Peaceful Nuclear Energy.Archive, 2006. The English version quoted from www.memri.org, August 30, 2006.

Farsnews, Mehrnews, Hamshahri online (2007) Iran Seizes 15 British Seamen.The English version quoted from Washington Post, March 24, 2007

Fisher, W. R. (1987). Human Communication as Narration: Toward a Philosophy of Reason, Value, and Action, Columbia: University of South Carolina Press.Fisher 1997

Fisher, W.R. (1985). The narrative paradigm: In the beginning. Journal of communication 35 (4): 74-89.

ISNA (Iran), July 17, 2009

Kuhn, Thomas S. (1999) 'Remarks on Incommensurability and Translation', in Rema Rossini Favretti, Giorgio Sandri and Roberto Scazzieri (eds) Incommensurability and Translation: Kuhnian Perspectives on Scientific Communication and Theory Change, Northampton MA and Cheltenham: Edward Elgar, 33-7.

Landau, M. (1997) 'Human Evolution as Narrative', in Lewis P. Hinchman and Sandra K. Hinchman (eds) Memory, Identity, Community, The Idea of Narrative in the Human Sciences, Albany: State University of New York Press, 104-18.

Los Angeles Times(2005)Hard-Liner Wins Decisively in Iran Presidential Election, , June 25, 2005

Mehrenews(2004) 'A Legal Ruling - Or the First Link in the Row of Dominos? Avaiblable online at http://www.mehrnews.com/fa 
/NewsDetail.aspx?NewsID=140761. The English news available at http://www.memri.org/report/en/0/0/0/0/0/0/1307.htm MEMERI, July 12, 2009

MEMERI, June 18, 2010)

MEMRI, August 30, 2006.

MEMRI, July 17, 2009

New York times, December 7, 2011

News channel subtitle, ISNA Headline) 26 urdibehesht, 1012)

Obama, B.(2009). Opening Speeches in sermon of achieving Noble prize.http://www.nobelprize.org/mediaplayer/index.php?id=1552

Online Britannica Encyclopedia (2012).

Persian Hub TV (2001) Iran election documentary women voting., June 28, 2001. Also available online at http://www.youtube.com /watch?v=m4Fw31157ws

Polkinghorne, D. E. (1995) Narrative configuration in cualitative analysis, in J. Amos Hatch and RichardWisniewski (eds) Life History and Narrative, London and Washington DC: The Falmer Press, 5-23.

UC TV (2003) .Interview with Shirin Ebadi, Noble Peace Prize Winner in 2003.www.UC TV.TV

Washington Post, March 24, 2007 